\title{
CINE Y GLOBALIZACIÓN EN IBEROAMÉRICA: EL PAPEL DE LAS COPRODUCCIONES
}

\author{
SANTIAGO JuAN-NAVARRO \\ Florida International University
}

\section{INTRODUCCIÓN}

La coproducción determina un importante eje de transformación socioespacial en las industrias audiovisuales, en cuanto espacio en el que la economía de libre mercado que borra las fronteras se encuentra con iniciativas culturales partidarias de definir límites territoriales, al abrigo del inestable signo de la nación. (Miller 2005: 143)

Si bien el fenómeno de la globalización no ha vaciado de sentido por completo "Io nacional", lo cierto es que cualquier actividad económica en nuestros días (y el cine es un fenómeno tanto cultural como comercial) se ve afectada por contratos y acuerdos internacionales, transnacionales o multinacionales, fuentes de inversión, mercados y regulaciones. De entre todas las industrias culturales, la del audiovisual es una de las que ha experimentado un mayor flujo de intercambios globales en los últimos años (García Canclini 1999: 155). Dada la precariedad de la industria cinematográfica en los países latinoamericanos, el sistema de coproducciones se ha convertido en una de las pocas alternativas para su supervivencia. Desde finales del siglo $\mathrm{xx}$, asistimos a una proliferación sin precedentes de interacciones entre el norte y sur de las Américas y entre ambos lados del Atlántico. Las coproducciones han contribuido a dar continuidad a las cinematografías iberoamericanas (Caballero 2006: 1), pero, al mismo tiempo, han abierto también un largo debate sobre los desequilibrios entre los países participantes y los efectos que a medio y largo plazo pueden tener en la transformación de las identidades nacionales y regionales. En su búsqueda de mer- 
cados internacionales, muchas de estas películas tienden a diluir sus referentes culturales en un estilo híbrido que no siempre ha sido bien recibido por la crítica (Alvaray 2011: 70). Es precisamente esa naturaleza híbrida y la pugna que en ellas sostienen simultáneamente impulsos de homogeneización y heterogeneización (de igualdad y diferencia), lo que hace de ellas un producto característico de la globalización (García Canclini 1999, Martín Barbero 2002). Es lo que las ha hecho también "sospechosas" ante los representantes del pensamiento esencialista, que no acaban de aceptar que la identidad no es un estado, sino un proceso, y que no puede ser aprehendida sino dentro de la lógica del cambio social.

A simple vista, podría parecer que asistimos de nuevo al debate generacional entre "apocalípticos e integrados" que Umberto Eco teorizó en los sesenta para describir las difíciles relaciones de los intelectuales con la cultura de masas. Es precisamente esa década la que algunos críticos latinoamericanos ven con nostalgia por haber representado un boom en la consolidación de imaginarios nacionales y continentales a través del cine y la cultura popular. No en balde fue la época que vio surgir el llamado "nuevo cine latinoamericano" por oposición al cine de Hollywood, en medio de un clima político enfervorecido por el reciente triunfo de la revolución cubana. Frente al debilitamiento de las señas de identidad que conlleva la globalización, los sesenta estuvieron marcados por expresiones culturales de signo utópico que parecían anunciar una nueva era dominada por la consolidación de imaginarios simbólicos autóctonos: "[s]e dice que en los años sesenta los latinoamericanos no iban al cine a divertirse, sino para aprender a ser mexicanos, argentinos, brasileños. En esos tiempos, los medios, incluida la radio [...] y el cine -que respondía a un proyecto de construcción nacional como gran narrativa popular- jugaron un papel clave en la gestación de culturas nacionales" (Garretón et al. 2003: 190). Pero lo cierto es que ni el panorama político resultó tan prometedor como se esperaba (pronto empezó el desencanto revolucionario y la interminable sucesión de dictaduras militares) ni la producción cultural se hizo sobre la nada (frente al rechazo del modelo norteamericano se cayó frecuentemente en el mimetismo del neorrealismo italiano o del cine de autor europeo).

Para entender cabalmente el fenómeno de las coproducciones dentro del marco de la globalización es importante explorar, siquiera brevemente, el marco político, económico y cultural en el que surgen, así como sus orígenes en el contexto iberoamericano. Las coproducciones transnacionales, que empezaron a acaparar los mercados durante los noventa y terminaron por imponerse a fines de la década, aprovecharon el vacío resultante del desmantelamiento de las industrias nacionales como resultado de las políticas neoliberales del momento y retomaron una tradición de intercambios desiguales con Europa y los Estados Unidos.

\section{LA INDUSTRIA CINEMATOGRÁFICA Y LAS POLÍTICAS NEOLIBERALES EN LATINOAMÉRICA}

Los Estados latinoamericanos, que han empobrecido los presupuestos y las acciones culturales por la política neoliberal, mantienen mayor presencia to- 
davía en la administración de los bienes ligados a la identidad territorial: sitios arqueológicos, museos, promoción del arte y las artesanías nacionales. Pero ceden a las empresas privadas las industrias audiovisuales, o sea los sectores más dinámicos del desarrollo cultural, donde se producen más innovaciones y se logran repercusiones masivas. En estos circuitos, en los que se registra la mayor trasnacionalización y desterritorialización de la cultura, la voz y las imágenes ahora son propiedad casi exclusiva de los empresarios. (García Canclini 1993b: 27)

Desde los años noventa venimos asistiendo al surgimiento de un nuevo paradigma en los mecanismos de producción y distribución del cine en Latinoamérica. Los momentos de aparente expansión han sucedido a otros de crisis extrema. En cada uno de esos periodos los éxitos aislados de ciertos títulos se han producido, a veces, en medio de industrias nacionales frágiles en donde los centros de decisión están cada vez más alejados de entornos geográficos específicos y dependen, en cambio, de alianzas y acuerdos transnacionales. Las políticas gubernamentales de regulación (o desregulación) de la industria cinematográfica se han venido sucediendo a un ritmo vertiginoso. Es difícil generalizar pasando por alto las coyunturas socio-económicas y políticas de cada país, pero puede afirmarse que tras un periodo de crisis extrema, que se correspondería con la primera mitad de la década de los noventa, se produjo un repunte del cine iberoamericano en el que actuaron como catalizadores tanto la expansión de la economía mundial como el surgimiento de nuevas formas de financiamiento y distribución.

La crisis de comienzos de los 90 estuvo directamente relacionada con el descenso (en algunos casos el desmantelamiento) del proteccionismo gubernamental, resultado de las políticas neoliberales que se extendieron por gran parte de Latinoamérica durante aquellos años. En gran medida, el espacio que dejaron vacante las administraciones públicas fue ocupado por el sector privado y las multinacionales del espectáculo. De especial relevancia fue el papel de la Motion Picture Association of America (MPAA), organización que incluye a los grandes estudios de Hollywood y que en los noventa penetró agresivamente en los mercados globales en crisis. Como se deduce de sus propios estatutos, la finalidad de su rama para América Latina (MPAA-AL) es defender los intereses de sus compañías en cada sector de la distribución -salas, TV, TV de pago, DVDs y nuevas tecnologías-mediante actividades dirigidas a mejorar su acceso a los mercados y proteger sus derechos sobre la propiedad intelectual. La MPAA-AL también ha venido colaborando con los institutos cinematográficos nacionales y otras agencias gubernamentales para promover marcos legislativos que favorezcan la coproducción con otros países. De hecho, a partir de 1996, las compañías de la MPAA pusieron en marcha una nueva dinámica de colaboración con los productores de Brasil, México y Argentina y con redes de distribución regionales que ha servido para la promoción y distribución internacional de filmes latinoamericanos a escalas nunca vistas. Esto, unido, a los acuerdos de coproducción con consorcios europeos, de los que hablaré más adelante, ha sentado la base para una circulación sin precedentes del cine latinoamericano a escala mundial. La 
"colaboración", por supuesto, no es desinteresada. Como ha subrayado Frédéric Martel, "desde principios de la década de 1990, las industrias del entertainment ocupan la segunda posición en las exportaciones estadounidenses, detrás de la industria aeroespacial. Como el mercado del cine está estancado en Estados Unidos y los costes de producción aumentan, los estudios se ven abocados a adoptar una estrategia comercial planetaria" (2010: 33) ${ }^{1}$.

En Brasil una de las primeras medidas que tomó el nuevo presidente electo Fernando Collor de Mello (1990-1992) fue la eliminación de todo tipo de subsidios para el mundo de la cultura. En nombre de la economía del libre mercado, se llevó a cabo una reducción drástica del aparato del Estado y una privatización de sus sectores estratégicos. Esto tuvo un impacto devastador para el mundo del cine. Se cerraron la Empresa Brasileira de Filmes (Embrafilme), que se había creado en 1969, y O Conselho Nacional de Cinema (Concine), fundado en 1975, lo que causó un descenso dramático en la producción y distribución del cine nacional (Johnson 2007: 87). Durante varios años el cine brasileño quedó reducido a mínimos históricos, consiguiendo recuperarse solo hacia finales de la década, en un lento proceso conocido como la "retomada", un proceso que habría de culminar con los éxitos internacionales de las multipremiadas Central do Brasil (1998), de Walter Salles, y Cidade de Deus (2002), de Fernando Meirelles y Katia Lund. Para 2003 la producción nacional había conseguido recuperar un $22 \%$ del mercado doméstico ${ }^{2}$. Pero, como bien señala Randal Johnson, la recuperación no fue el resultado del éxito de uno o dos filmes, sino del cambio en el paradigma de producción que marcó la creación de Globo Filmes, división cinematográfica del monopolio mediático Globo TV $(2007: 88)^{3}$, junto a una nueva red de alianzas que habría de cambiar la forma de hacer cine y de distribuirlo en Brasil.

\footnotetext{
${ }^{1}$ Desde sus oficinas en Río de Janeiro, La MPAA-AL controla la mayor parte de la distribución y exhibición en Iberoamérica y una buena parte de su producción, bajo la forma de acuerdos multilaterales con muchos de los países del área. Aunque en el centro de la filosofía de la MPAA está la defensa del mercado libre y la lucha contra el proteccionismo estatal en Latinoamérica, "es bastante paradójico defender el comercio 'libre' desde una posición de dominio oligopólico de un mercado, como es el caso de la distribución de películas en todo el orbe" (Sánchez Ruiz 2004: 12).

2 Datos procedentes de ANCINE (Agência Nacional do Cinema) revelan que en los últimos seis años los títulos nacionales exhibidos en salas representan cerca de una cuarta parte del total, lo que, comparado con la abrumadora mayoría de películas extranjeras exhibidas a comienzos de los noventa, confirma la recuperación del cine brasileño en fechas recientes. En 2009, un filme doméstico, Tropa de Elite (2007), recibió el Oso de Oro en el Festival de Berlín y su secuela (Tropa de Elite 2 - O Inimigo Agora é Outro), estrenada en 2010, se convirtió con sus once millones de espectadores en la película brasileña más vista de todos los tiempos, algo sorprendente para un filme cuya producción y distribución (a cargo de Zazen Produções, RioFilme y Globo Filmes) no estaban ligadas a las majors estadounidenses.

${ }^{3}$ La empresa Globo Filmes fue fundada en 1998 por Roberto Marinho. Sus películas obtuvieron más del $90 \%$ de los ingresos en taquilla del cine nacional y más del 20\% del mercado total. Globo Filmes tiene también los derechos de la distribución de las películas que produce. Hasta la fecha ha producido aproximadamente cien largometrajes con una audiencia que se calcula en alrededor de setenta millones de espectadores en salas de cine. También ha formado alianzas con más de cuarenta productores independientes. La presencia de esta empresa en el mercado del cine brasileño ha suscitado división de opiniones. Cineastas y productores como Luiz Carlos Barreto y Cacá Diegues son favorables, mientras que otros, como Walter Salles y Nelson Pereira dos Santos, están en contra, alegando la falta de valor artístico y cultural de sus productos.
} 
Las políticas neoliberales Ilegaron a México en fechas similares, alcanzando su apogeo bajo la administración de Carlos Salinas de Gortari (1988-1994). La nueva Ley Federal de Cinematografía de 1992 rompía con el proteccionismo de regulaciones anteriores al ir reduciendo progresivamente la cuota mínima de tiempo de pantalla dedicada a la producción nacional ${ }^{4}$. Si la Ley de 1941, por ejemplo, exigía un 50\%, en 1993 el porcentaje se limitaba ya a un 30\%, hasta llegar a solo el 10\% en diciembre de 1997 (Sánchez Ruiz 2004: 27). El resultado fue similar al de Brasil. En 1992 quebró la distribuidora estatal Películas Nacionales y un año después se privatizaba la Cadena Operadora de Teatros, encargada de la exhibición de una buena parte del cine mexicano (Sánchez Ruiz 1998: 106). Para 1994, cuando entra en vigor el Tratado de Libre Comercio de América del Norte (TLCAN), la industria cinematográfica mexicana atravesaba uno de los peores momentos de su historia, sin poder competir en igualdad de condiciones con sus vecinos del norte. La producción a partir de ese momento quedó en manos de la iniciativa privada y de una progresiva dependencia del capital transnacional. Y lo que es peor, a diferencia de Canadá, que incluyó el cine como excepción cultural dentro del Tratado, México no hizo algo parecido y su cine ha tenido que competir con el de los demás miembros al mismo nivel que lo ha hecho con la industria automotriz o la agricultura (Ruiz Guzmán 2011: 16). A pesar de esta situación, el siglo XXı se abrió con tres de las películas más populares en su historia: Amores perros (México, 2000), de Alejandro González Iñárritu; Y tu mamá también (México/España, 2001), de Alfonso Cuarón; y El crimen del Padre Amaro (México/España/Argentina/Francia, 2002), de Carlos Carrera. La consagración de los directores mexicanos en el mercado internacional no se produjo, sin embargo, hasta unos años después, cuando, además del capital europeo, las coproducciones (en algunos casos rodadas en inglés) incluyeron también compañías norteamericanas: Babel (2005), de Iñárritu, se coprodujo entre Francia, EE.UU. y México, y fue distribuida por Paramount; mientras que Children of Men, de Cuarón, se financió exclusivamente con fondos del Reino Unido y EE.UU., con distribución internacional a cargo de Universal Pictures. A estos dos nombres habría que añadir también el de Guillermo del Toro, director mexicano con una larga experiencia tanto en Hollywood (Mimic, 1997; Blade II, 2002; Hellboy, 2004), como en coproducciones hispano-mexicanas (El espinazo del diablo, 2001; El laberinto del fauno, 2006).

En el caso de Argentina, la producción cinematográfica se vio igualmente afectada por los radicales cambios políticos y económicos por los que atravesó el país durante las últimas décadas del siglo xx. Tras el retorno a la democracia, se produjo una normalización de la vida política que tuvo como resultado un aperturismo en el mundo del cine. En el periodo que va desde 1984 a 1988

\footnotetext{
4 Recordemos que, aunque la cinematografía mexicana había sido en gran medida "estatizada" durante el sexenio de Luis Echeverría (1971-1976), los gobiernos que le sucedieron siguieron una orientación radicalmente distinta e invariablemente tendieron a devolver el control de la producción, la distribución y exhibición al sector privado. Según García Canclini (2005), en México, las películas auspiciadas por el Estado, que representaban el 26,5\% del cine producido en el país en el sexenio 1971-1976, bajaron al 7\% entre 1985 y 1988.
} 
(los años centrales de la presidencia de Raúl Alfonsín: 1983-1989) el énfasis, sin embargo, se puso en el cambio político y cultural, más que en el económico e industrial. Como señala Octavio Getino, la función que se le asignó al cine fue la de embajador en el exterior de la nueva Argentina, surgida tras la larga noche de las dictaduras militares. No existía, sin embargo, un programa claro de reformas estructurales del sector (como tampoco lo existía entre la oposición peronista). Determinados filmes gozaron, a veces indiscriminadamente, del apoyo gubernamental y fueron muy bien acogidos en festivales internacionales. Tal fue el caso de Camilla (1984), de María Luis Bamberg; El exilio de Gardel (1985), de Pino Solanas; y La historia oficial (1985), de Luis Puenzo (Getino 2005: 42) Con la llegada al poder de Carlos Menem (1989-1999) y la sanción de la llamada Ley de "Emergencia Económica" en 1989, se privatizaron los medios de radiodifusión y se suspendieron todas las ayudas y subvenciones en el campo de la cultura. Aunque la industria cinematográfica se vio inicialmente afectada por los recortes, luego de intensos debates (y de la presión ejercida por el Instituto Nacional de Cinematografía), el presidente Menem accedió a excluir al cine de los alcances de la Ley. Este hecho explicaría, según Getino, la relativa excepcionalidad que el cine argentino vivió desde 1990, en el marco de una política económica que arrasó con el proteccionismo de la industria nacional y la promoción de su cultura (2005: 54-55). Como en el caso de Brasil, tras un periodo de declive en la primera mitad de los noventa, se produjo una expansión de la producción a finales de la década. Con la puesta en marcha en 1994 de la nueva Ley del Cine, aprobada un año antes, la creación de centros para la formación de cineastas, y el comienzo de las coproducciones se dio inicio a un periodo de esplendor que se ha conocido como el Nuevo Cine Argentino (Falikov 2003: 49). En aquellos años tuvo lugar un boom del cine independiente realizado por jóvenes directores salidos de las nuevas universidades del cine. Películas como Picado fino (1994), de Esteban Sapir, Pizza, birra, faso (1998), de Bruno Stagnaro, y Mundo grúa (1999), de Pablo Trapero, tuvieron gran impacto en los festivales y en los circuitos alternativos. Con la nueva década se abrió, asimismo, un periodo en el que el cine nacional, bajo un nuevo régimen de coproducciones, pudo llegar a ser competitivo en taquilla. Así lo demuestran los dos filmes que abren y cierran la década: Nueve reinas (2000), de Fabián Bielinsky, uno de los éxitos cinematográficos del momento, con más de un millón y medio de espectadores; y El secreto de sus ojos (2009), de Juan José Campanella, que recibió el Óscar a la mejor película extranjera en 2010 y que con sus dos millones y medio de espectadores se convirtió en la película argentina más taquillera de las últimas décadas.

En el caso de Brasil, México y Argentina observamos, pues, una dinámica similar respecto a sus industrias audiovisuales: tras varias décadas de proteccio-

\footnotetext{
${ }^{5}$ Getino subraya la repercusión internacional del cine argentino "de la democracia", que obtuvo entre ciento cincuenta y doscientos premios en festivales internacionales durante el periodo, aunque no se sustentaran necesariamente en los méritos de los filmes sino, más bien, en razones de política internacional. Simultáneamente, con la desaparición de la censura las pantallas argentinas, se vieron inundadas por subproductos cinematográficos como el soft-porno vernáculo, que al igual que la "porno-chanchada" en el Brasil post-dictatorial, fue uno de los productos fílmicos más rentables durante aquellos años (Getino 2005: 43).
} 
nismo público, las políticas neoliberales a finales de los ochenta y comienzos de los noventa, vinieron acompañadas de recortes a los programas sociales y culturales, incluyendo las inversiones estatales y otros incentivos para el sector cinematográfico. Esta situación alcanzó su momento culminante en 1990 cuando los gobiernos de estos tres países (los productores de cine mayores de la región) anunciaron medidas draconianas que en algunos casos llegaron prácticamente al desmantelamiento del sector público, clave en la supervivencia del audiovisual. Este es el contexto en el que Néstor García Canclini se preguntaba en un artículo publicado en 1993, “¿Habrá una cine latinoamericano en el año 2000?". Sin embargo, García Canclini no solo se estaba refiriendo al drástico descenso en las cifras de producción y distribución en el continente. También capturaba un sentido, generalizado en aquel momento, de que en el nuevo orden neoliberal imperante tras el fin de la Guerra Fría, los productos culturales eran vistos crecientemente como meros objetos de consumo y en el que la visión utópica del Nuevo Cine Latinoamericano, con su búsqueda de una autonomía cultural y una identidad nacional (y continental), se había terminado por convertir en una quimera del pasado. Una vez que cambió la situación internacional habría de cambiar también la forma de producir y consumir cine. Surgió así, a finales de los noventa, una nueva era de coproducciones internacionales subvencionadas por entidades corporativas globales, pero a veces también por consorcios públicos transnacionales. Si bien, en algunos casos, los agentes implicados han estado localizados en Latinoamérica, en la mayoría se observa una influencia dominante del capital español. Valiéndose de algunas convenciones estéticas de las cinematografías nacionales en las que se inscribían, estas coproducciones seguían aspirando a diferenciarse del cine de Hollywood, pero también a competir con él en un marco crecientemente globalizado.

\title{
3. Arqueología de las coproducciones con España
}

\begin{abstract}
España constituye la sexta parte de la población universal que habla en casteIlano. Ya no solo nos interesa nuestro mercado interior, nos interesa aún más nuestro mercado de América, hoy monopolizado por Estados Unidos, que, lentamente, van desespañolizando todo aquello que lleva nuestro espíritu racial. Moral y materialmente, España necesita de una industria cinematográfica nacional, que a la postre sería una industria cinematográfica hispanoamericana, pero que estaría centralizada en nuestra península. (Primer Congreso Hispanoamericano de Cinematografía 1932: 51)
\end{abstract}

Las coproducciones tienden a considerarse como un fenómeno reciente en Iberoamérica, olvidando, sin embargo, que el origen de las relaciones entre las cinematografías de España y Latinoamérica se remonta nada menos que al periodo de transición entre el cine mudo y el sonoro. Por parte española quizá habría que atribuir este olvido a un intento por encubrir los orígenes mercantilistas y la ideología ultraconservadora que envolvió desde sus comienzos las relaciones desiguales entre ambas. Y es que los intercambios cinematográficos entre Iberoamérica y la Península estuvieron fuertemente marcados en sus orí- 
genes por la ideología de la Hispanidad. De hecho, podría afirmarse que, hasta cierto punto, lo han seguido estando hasta ahora, ya que Iberoamérica ha ocupado (y sigue ocupando) un lugar preferente en la política exterior de todos los gobiernos españoles, desde comienzos del siglo pasado hasta el presente, sin importar demasiado la ideología de los partidos gobernantes o incluso el tipo de régimen vigente (dictadura, república o monarquía). En cierto sentido, hay algo de nostalgia neocolonial, o al menos de paternalismo cultural, en gran parte de los congresos iberoamericanos, convenios multilaterales, tratados de cooperación, alianzas estratégicas o simples declaraciones de buenas intenciones que periódicamente emanan de los representantes políticos, instituciones públicas y, más recientemente, de las multinacionales españolas con presencia en Latinoamérica. Si bien en la actualidad estas actitudes tienden a ser muy sutiles, para no herir susceptibilidades, en sus primeros momentos tuvieron un carácter ostentosamente propagandístico. De hecho, el Primer Congreso de la Cinematografía Hispanoamericana, aunque celebrado en Madrid en octubre de 1931 (es decir, a comienzos de la Segunda República), fue un proyecto que se gestó años atrás, durante la dictadura de Miguel Primo de Rivera, y respondía a la necesidad de buscar una cinematografía nacional de proyecciones transatlánticas en respuesta al reto del cine sonoro norteamericano. Se creía que articulando un frente cinematográfico panhispánico liderado por España podría esta recuperar su hegemonía, al menos en el campo de la cultura (Gubern 1997).

En 1928 Fernando Viola, un entrepeneur a cargo del noticiero Ediciones Cinematográficas de la Nación, hizo una propuesta al gobierno que presentó públicamente en el II Congreso Nacional del Comercio Español en Ultramar. Viola planteaba la necesidad de firmar acuerdos arancelarios con las cinematografías hispanoamericanas, realizar noticieros que sirvieran de propaganda del hispanoamericanismo y producir filmes que lavaran el honor mancillado por la Leyenda Negra en torno a la colonización española. Detrás de su propuesta planeaba la necesidad de hacer frente a la conquista del mercado cinematográfico por parte de Estados Unidos explotando las posibilidades que abría el mercado de habla hispana. Las sugerencias de Viola fueron bien recibidas entre los sectores más reaccionarios de la cultura y la política españolas, pero, paradójicamente, no se habrían de materializar hasta el triunfo de la Segunda República. Sería curiosamente Francisco Largo Caballero (el "Lenin español"), quien, como nuevo Ministro de Trabajo, diera luz verde al proyecto. El Congreso, que tuvo finalmente lugar en Madrid del 2 al 12 de octubre de 1931, se enmarcó dentro del afianzamiento de lazos con Hispanoamérica que caracterizó la política exterior republicana y fue solemnemente inaugurado por el Presidente Niceto Alcalá Zamora. Como apunta Alberto Elena, "en la práctica el Congreso se revelaría completamente estéril más allá de sus encendidas manifestaciones retóricas. La adopción de apenas unas cuantas medidas fiscales o la creación de un titubeante Consejo Nacional de Cinematografía distaban mucho de justificar las expectativas de los visionarios congresistas" (2005: 7).

La Guerra Civil dio al traste con la industria cinematográfica española, pero permitió el intercambio con Iberoamérica a través del exilio de gran parte 
de sus técnicos y realizadores. Fue precisamente ese exilio el elemento más enriquecedor y genuino dentro de las relaciones culturales entre las dos orillas. Los organismos de cultura hispánica y los encuentros posteriores, celebrados ya en pleno franquismo retomaron el tono reaccionario y paternalista del Primer Congreso de una forma especialmente agresiva durante la inmediata posguerra. En todos ellos se fue consolidando un discurso hispanoamericanista en torno a tres puntos principales: 1) la visión de Hispanoamérica como mercado natural para la industria cinematográfica española; 2) la idea de raza hispana como comunidad espiritual cifrada en una lengua común; y 3) la intensificación del discurso antinorteamericano, mediante acusaciones de imperialismo a Hollywood.

La fundación en 1940 del Consejo de la Hispanidad, que cinco años después fue reconvertido en el Instituto de Cultura Hispánica, se enmarcaba dentro de la política beligerante del primer franquismo dominado por la Falange y otros sectores filofascistas. Su creación tiene sus orígenes en el bloqueo del régimen por las democracias occidentales y en la búsqueda de aliados naturales en lberoamérica. La política neocolonial del Consejo de la Hispanidad y sus nostalgias imperiales quedaron ampliamente reflejadas en una de sus producciones más paradigmáticas: Raza (1941), de José María Sáenz de Heredia, con guión del propio Francisco Franco. A medida que la dictadura fue transformándose, su discurso sobre la Hispanidad fue adoptando un tono menos virulento, pero igualmente paternalista. El Instituto de Cultura Hispánica $(\mathrm{ICH})$ siguió promocionando el cine de proyección transatlántica, pero dentro de un proyecto diplomático que buscaba romper el aislamiento político y cultural de la dictadura en los años en que estuvo sometida a las sanciones diplomáticas decretadas por la ONU en diciembre de $1946^{6}$.

Del 27 de junio al 4 de julio de 1948 se celebró en Madrid el II Congreso Cinematográfico Hispanoamericano, donde se reunieron los organizadores españoles con representantes de Argentina, Cuba y México. Coincidiendo con las premisas fundacionales del ICH, la finalidad del Congreso no era otra que seguir intentando acabar con el cerco internacional ofreciendo una imagen menos belicosa y más aceptable ante las democracias occidentales ${ }^{7}$. Como consecuencia de este congreso, se firmaron varios acuerdos, entre ellos el que propiciaba la creación de una Unión Cinematográfica Hispanoamericana. Se sentaron de esta forma las bases para un sistema de cooperación internacional que se tradujo en gran cantidad de coproducciones entre España, México y Argentina. La primera y

\footnotetext{
${ }^{6}$ Para un análisis de la evolución del concepto de Hispanidad y del papel del ICH en las estrategias de legitimación del franquismo, véase Juan-Navarro (2006).

${ }^{7}$ A esa intención no era ajeno el Sindicato Nacional del Espectáculo, que cobró un especial protagonismo en el encuentro. En opinión de Marina Díaz López, "es notorio resaltar la intención conciliatoria que movía al Sindicato Nacional del Espectáculo, que era la de evitar cualquier matiz político en la reunión, y prueba de ello es la presencia de la delegación mexicana, país con el que se carecía de relaciones diplomáticas -que no se reemprendieron hasta 1976-. El acercamiento exigía tacto, y prueba de ello es que la cuestión preliminar se hizo recaer sobre el hecho de que no había conocimiento real de las tres cinematografías entre sí, por lo que la reunión se planteó como un 'certamen'; es decir, concurso de películas. Así se manifestaba la intención de dotar al encuentro de un carácter primordialmente cultural y se salvaguardaba institucionalmente la pátina de hermanamiento hispano" (1999: 146).
} 
más paradigmática fue Jalisco canta en Sevilla (1948), de Fernando de Fuentes, financiada entre México y España, y con Jorge Negrete y Carmen Sevilla encarnando las esencias nacionales de los dos países coproductores (Urrero Peña 2002) ${ }^{8}$.

En los años cincuenta se podían ver en las salas comerciales españolas muchas películas de procedencia mexicana y argentina, al igual que era común ver en los cines de México D.F. o Buenos Aires filmes españoles, principalmente aquellos de carácter más folklórico y pintoresco ${ }^{9}$. Por esa época, mientras Nini Marshall, María Félix y Rubén Rojo rodaban películas en España, Lola Flores, Sara Montiel, Carmen Sevilla y Jorge Mistral trabajaban también en estudios iberoamericanos. En lo sucesivo, las relaciones entre las cinematografías de España e Hispanoamérica empezaron a descentralizarse, escogiendo como sedes para los Congresos y Encuentros las capitales de diversos países iberoamericanos. Los acuerdos de coproducción aumentaron, además, de forma exponencial. Si en los años cuarenta solo se coprodujo un filme, en los cincuenta la cifra ascendió a cuarenta y dos títulos, en los sesenta a sesenta y ocho, en los setenta a ochenta y cuatro, y en los noventa a ciento veintiséis. Entre 2000 y 2006 se realizaron más de doscientas coproducciones (Villazana 2008: 66) ${ }^{10}$.

\section{El fondo Ibermedia: ¿COOPERACIÓn O neOCOlONIALISMO CULTURAL?}

Sin diálogo no hay conocimiento, sin instituciones adecuadas no hay investigación con un mínimo de continuidad. Quizás podamos reemplazar el espíritu de competencia por el de cooperación en torno a unos objetivos limitados, de común interés, que no requieran demasiada burocracia para su implementación. (Paranaguá 2001: 14)

Las complejas décadas de los ochenta y noventa asistieron al nacimiento de nuevas formas de cooperación cinematográfica destinadas a paliar las crisis

\footnotetext{
8 Para una relación exhaustiva de estas coproducciones, véase el ensayo de Alberto Elena (2005: 36-41).

${ }^{9}$ Román Gubern (1997) puntualiza que no siempre fueron bien recibidos tales intercambios por el público menos informado: "No siempre el rudo castellano peninsular fue bien aceptado en las salas de proyección iberoamericanas, ni los modismos mexicanos bien entendidos por el público español. Creo que, como principio general, el exotismo lingüístico solo fue admitido por los públicos urbanos con un cierto nivel educativo, aunque a veces este exotismo jugó a favor de la popularidad de ciertas estrellas. Resulta inconcebible el carismático Carlos Gardel con acento de Valladolid, pues su duende solo puede ser porteño, aunque naciese en Toulouse, Francia".

10 Además de estas cifras, que se refieren a las coproducciones con Latinoamérica, no podemos pasar por alto el número creciente de coproducciones entre España y el resto de países europeos. Como señala Alejandro Pardo (2007: 138), tras la firma de los primeros acuerdos de coproducción con Italia (1953) y Francia (1955), el sistema de coproducción se consolidó de forma significativa en 1956, alcanzando su apogeo en 1965, año en que el $67 \%$ del total de películas realizadas fueron coproducciones internacionales. Entre 1950 y 1975 se realizaron novecientas treinta coproducciones, lo que supone un $40 \%$ del total de la producción española durante ese periodo. De las coproducciones bipartitas, un $50 \%$ se hicieron con Italia. Otros socios habituales fueron Francia, Argentina, Alemania, Estados Unidos, México y el Reino Unido. Eurimages, fondo paneuropeo de inversión en coproducciones multinacionales, fue establecido en 1989 dentro del Consejo de Europa y pronto se convirtió en el mayor programa de dinero público aplicado a la industria cinematográfica.
} 
del sector y los cambios en la industria derivados del nuevo orden mundial. Los canales de televisión, que habían puesto en práctica diferentes alternativas a la producción en los ochenta, extendieron la financiación al cine durante la siguiente década. Varios países europeos se mostraron interesados en la creación de convenios y fondos de ayuda con los países de la región. Fue el caso de Francia con Fonds Sud creado en 1984 y de Holanda con Hubert Bals en 1988. Si bien los Estados Unidos no crearon un cuerpo regulador a largo plazo para las coproducciones con Latinoamérica, la Motion Picture Association of America (MPAA) ha establecido, sin embargo, acuerdos con algunas empresas líder en la industria, tales como Patagonik Films en Argentina (Villazana 2008: 66).

En la década de los noventa, como parte de las políticas orientadas a incrementar el intercambio cultural, comenzó a desarrollarse también la práctica de reuniones de ministros y responsables de cultura de Iberoamérica, así como las denominadas Cumbres Iberoamericanas de Jefes de Estado y de Gobierno. La primera de estas tuvo lugar en Guadalajara, México, en julio de 1991 y destacó entre los temas tratados el referido a Educación y Cultura. En la III Cumbre de julio de 1993, efectuada en Salvador de Bahía, Brasil, se incorporó en este tipo de encuentros el tema de la coproducción cinematográfica. Estos avances fueron producto, también, de la labor intensa que desarrollaron los organismos fílmicos de la región, particularmente los de Argentina, Brasil y España, para encontrar formas de cooperación regional que permitiesen afrontar los nuevos desafíos de la industria y la cultura audiovisual iberoamericana. De ese modo, a lo largo de los años ochenta y noventa se produjeron sucesivos encuentros de responsables del cine, orientados a definir acuerdos de integración que atendiesen de manera particular los temas del mercado común regional y de las coproducciones. El más importante de ellos fue el ratificado durante la Cumbre Iberoamericana de Jefes de Estado y de Gobierno que tuvo lugar en Isla Margarita, Venezuela, en 1997, y que incluyó la creación del Fondo Iberoamericano de Ayuda IBERMEDIA, destinado a la creación de un espacio audiovisual iberoamericano. José María Otero, situado por aquel entonces al frente del Instituto de la Cinematografía y de las Artes Audiovisuales (ICAA), describía así la filosofía y arbitraje del Fondo:

Ibermedia tiene como fin la integración y la cooperación cultural por medio del fomento de las coproducciones a las que se destina el $60 \%$ del Fondo; a impulsar la distribución y la promoción, con el 30\% del Fondo; y a mejorar la formación, el 5\% del Fondo, y el desarrollo de guiones, con otro 5\%. Las primeras ayudas se concederán el 28 y 29 de noviembre de 1997 en La Habana. El Fondo está dotado por las aportaciones de los países miembros de Ibermedia. Pueden ser miembros todos los países que forman la Conferencia de Autoridades Cinematográfica de Iberoamérica o países invitados. (Otero 1999: 26)

El núcleo del Fondo consiste en un programa de estímulo a la coproducción de películas a través de convocatorias anuales. Ibermedia se mantiene sobre la base de contribuciones variables de sus diecinueve países miembros: Argentina, Bolivia, Brasil, Chile, Colombia, Costa Rica, Cuba, Ecuador, España, Guatemala, México, Panamá, Paraguay, Portugal, Perú, Puerto Rico, República Dominicana, 
Uruguay y Venezuela. A diferencia de los países latinoamericanos, que aportan cantidades diferentes en función de su poder económico (oscilan entre $\$ 100.000$ y $\$ 150.000$, a excepción de Brasil, México y Argentina, que giran en torno al medio millón), España contribuye con aproximadamente $\$ 2$ millones anuales, siendo por tanto el mayor contribuyente, pero obteniendo a cambio la mayor parte del control. Las oficinas están en España y la mayor parte del personal es español, si bien la comisión intergubernamental se reúne cada año en un país diferente. Una española (Elena Villardel) está al mando de la Unidad Técnica de Ibermedia (UTI), que se encarga de la preselección de los proyectos presentados cada año. Algunos países miembros, como Perú y Bolivia, dependen por completo de la financiación de Ibermedia (Villazana 2008: 66) ${ }^{11}$.

\begin{tabular}{|c|c|c|c|}
\hline País & $\begin{array}{c}1^{\mathrm{n}} \\
\text { Convocatoria }\end{array}$ & $2^{2}$ Convocatoria & Total anua \\
\hline Argentina & 3 & 4 & 7 \\
\hline Bolivia & 9 & 3 & 12 \\
\hline Brasil & 4 & 13 & 17 \\
\hline Chile & 3 & 5 & 8 \\
\hline Colombla & 10 & 14 & 24 \\
\hline Costa Rica & 4 & 4 & 8 \\
\hline Cuba & 2 & 0 & 2 \\
\hline Ecuador & 4 & 6 & 10 \\
\hline España & 15 & 14 & 29 \\
\hline Guatemala & 0 & 0 & 0 \\
\hline México & 5 & 6 & 11 \\
\hline Panamá & 1 & 4 & 5 \\
\hline Perú & 3 & 5 & 8 \\
\hline Portugal & 5 & 5 & 10 \\
\hline Puerto Rico & 2 & 0 & 2 \\
\hline R. Dominicana & 0 & 2 & 2 \\
\hline Uruguay & 3 & 4 & 7 \\
\hline Venezuela & 8 & 2 & 10 \\
\hline Varios & 1 & 3 & 4 \\
\hline Total & 82 & 94 & 176 \\
\hline
\end{tabular}

Evolución de proyectos aprobados por año y modalidad (Programa Ibermedia 2011: 11)

\footnotetext{
11 En 2011, \$5.907.500 fueron destinados de manera directa para las ayudas a proyectos, lo que representa el $90 \%$ de su dotación económica total. El $10 \%$ de este monto fue destinado al coste de mantenimiento del programa. El reducido coste de funcionamiento y puesta en marcha de las actividades e intervenciones del mismo es uno de los aspectos mejor valorados del programa.
} 
Algunas de las películas que se han beneficiado del Fondo son: La ciénaga (Argentina/Francia/España, 1999); Plata quemada (Argentina/España/Uruguay, 2000); El crimen del padre Amaro (México/España/Argentina/Francia, 2002); El bonaerense (Argentina/Chile/Francia/Holanda, 2002); La puta y la ballena (Argentina/España, 2004); Machuca (Chile/España/Reino Unido/Francia, 2004); Habana Blues (Cuba/España, 2005); Rosario Tijeras (Colombia/México/España/Brasil, 2005); y Carancho (Argentina/Chile/Francia/Corea del Sur, 2010). Los siguientes gráficos y estadísticas procedentes del informe anual de 2011 ofrecen un resumen de la evolución anual de los proyectos y de las actividades más recientes de Ibermedia en el campo de la coproducción:

\begin{tabular}{|c|c|c|c|c|c|c|c|c|c|c|c|c|c|c|c|}
\hline Modalldad/Año & 1998 & 1999 & 2000 & 2001 & 2002 & 2003 & 2004 & 2005 & 2006 & 2007 & 2008 & 2009 & 2010 & 2011 & TOTAL \\
\hline DESARROLLLO & 32 & 30 & 21 & 24 & 15 & 25 & 21 & 31 & 51 & 61 & 69 & 67 & 60 & 72 & 579 \\
\hline COPRODUCCION & 15 & 15 & 23 & 26 & 26 & 30 & 32 & 35 & 46 & 49 & 52 & 67 & 69 & 57 & 542 \\
\hline FORMACIÓN & 25 & 27 & 49 & 32 & 35 & 5 & 9 & 9 & 12 & 12 & 15 & 19 & 24 & 25 & 298 \\
\hline $\begin{array}{l}\text { DISTRIBUCIÓN } \\
\text { PROMOCION }\end{array}$ & 46 & 42 & 22 & 13 & 13 & 16 & 10 & 20 & 16 & 11 & 0 & 4 & 7 & 3 & 223 \\
\hline DELIVERY & & & & & & & & & 6 & 11 & 10 & 6 & 13 & 14 & 60 \\
\hline EXHIBICION & & & & & & & & & & & & 6 & 4 & 5 & 15 \\
\hline TOTALES & 118 & 114 & 115 & 95 & 89 & 76 & 72 & 95 & 131 & 144 & 144 & 184 & 177 & 176 & 1730 \\
\hline
\end{tabular}

Número total de proyectos aprobados por convocatoria y país en 2011

(Programa Ibermedia 2011: 11)

Desde que Ibermedia comenzó sus actividades en 1998 se han sucedido las críticas en relación con su estructura de financiación, transparencia y relaciones de poder. Por lo que se refiere a la financiación, aunque esta se considera democrática, ya que cada país contribuye en función de sus posibilidades, el mayor donante del grupo es España y casi todas las operaciones logísticas se realizan en Madrid, donde están sus cuarteles generales. Si la cantidad aportada por España (muy superior a la de otros países) puede contemplarse como una donación y un beneficio para la organización en su conjunto, el Estado español no actúa de forma desinteresada (Falikov 2012: 308) ${ }^{12}$. Por otra parte, el dinero español proviene de AECID (Agencia Española de Cooperación Internacional

\footnotetext{
12 Los administradores de Ibermedia no consideran problemático que España tenga un poder de decisión mayor debido a su contribución monetaria mayoritaria al fondo. Víctor Sánchez, coordinador de coproducción y distribución, piensa que la posición de España está justificada cuando afirma que "dado que España financia la mitad del fondo, no me parece objetable que se le permita tener un mayor poder de decisión a la hora de supervisar muchos de estos proyectos" (Falikov 2012: 308).
} 
para el Desarrollo), una agencia gubernamental dependiente del Ministerio de Asuntos Exteriores. No podemos olvidar, además, que Ibermedia se crea en pleno proceso de penetración de las multinacionales españolas en Latinoamérica y dentro de un contexto al que Celestino del Arenal se ha referido como la "economización de la política exterior y muy en concreto de la política latinoamericana. Una economización directamente relacionada con el espectacular incremento de las inversiones españolas en América Latina a partir de mediados de los años noventa, que se produce especialmente en sectores regulados, muy visibles y sensibles para la opinión pública latinoamericana, con los problemas de imagen de España que pueden provocar" (2011: 264). Dado el marcado carácter ideológico que el iberoamericanismo ha tenido en la política exterior de la España moderna, no es extraño que el Programa Ibermedia sea visto por las autoridades españolas como una manera de ganar prestigio internacional, mientras que los latinoamericanos pueden pensar que la implicación de España responde a una relación paternalista y a un intento de mantener relaciones de privilegio sobre sus tradicionales áreas de influencia ${ }^{13}$. Si bien España pierde dinero en la empresa a corto plazo, gana en términos de prestigio al contribuir en la producción de filmes que en muchos casos son galardonados en los Festivales internacionales. Es por esto que algunos críticos, como Libia Villazana, llegan a calificar este sistema de coproducciones de neocolonial:

In contrast to Telefonica, the Ibero-American Aid Fund, Ibermedia, manifests its neocolonial discourse in a rather subtler manner -subtlety is one of the chief inherited features of neocolonialism. Spain has become a faultless example of what the term neocolonialism embodies. Spain marches into Latin America with its economic and cultural troops, just as the United States has done since 1823 -when President James Monroe with the assistance of his astute secretary John Quincy Adams launched the Monroe Doctrine. (Villazana 2008: 79)14

Los detalles en la financiación de las coproducciones del Fondo deben entenderse en la perspectiva del contexto económico global. España mantiene una ventaja monetaria cuando coproduce con naciones latinoamericanas pobres, como Cuba o Bolivia. El coste de una película rodada en esos lugares es mucho

\footnotetext{
13 Del Arenal señala cómo "las inversiones directas de las empresas españolas en América Latina conocieron entre 1995 y 2000 [los años en que precisamente se gestó lbermedia] un espectacular desarrollo y que esos flujos de inversión han continuado posteriormente [...]. En concreto, entre 1995 y 2000, América Latina se convirtió en el principal destino de la inversiones españolas, absorbiendo en promedio anual, el $60 \%$ de las mismas, mientras que la UE se situaba en segundo lugar, con el $26 \%$. Este elevado flujo de inversiones directas transformó a las empresas españolas, hasta el año 2000, en los segundos inversores internacionales en la región, apenas por detrás de los Estados Unidos" (2011: 264).

${ }^{14}$ A pesar de este tipo de críticas, un tanto hiperbólicas, Villazana reconoce aspectos positivos en este tipo de fondos de coproducción: "Without the support of Ibermedia, for instance, the director Francisco Lombardi would have not been able to produce the quantity of films he has made thus far. Furthermore, by continuing to direct and produce films, Lombardi has acquired substantial experience in the field. Coproductions have also received significant gratitude for being a vehicle, albeit deceptive in many cases, of international visibility (in Espinosa's sense) of those cultures depicted in those films" (2008: 82).
} 
más bajo para los productores españoles que si fuera rodada en la Península. Sin embargo, se tiende a insistir en que España pierde dinero en la empresa. Los países que, en cambio, aportaron cantidades más pequeñas obtuvieron un mayor beneficio a corto plazo. Según la información disponible en la web del Fondo, España obtiene menos dinero del que aporta: Perú y Bolivia reciben $\$ 1.70$ por cada \$1 que invierte España. Igualmente Brasil recibe $\$ 1.18$ por cada $\$ 1.00$ que aporta Portugal. Y el resto de los miembros ganan $\$ 1.60$ por cada $\$ 1$ español ${ }^{15}$. Pero estas cifras no afectan lo más mínimo al hecho innegable de que España mantiene su lugar hegemónico en la industria cinematográfica iberoamericana y tiene en Latinoamérica su mercado más prometedor.

Hay otras ventajas de las que disfrutan los productores españoles en comparación con sus homólogos latinoamericanos. Por un lado, reciben además los subsidios otorgados por el Ministerio de Cultura, que reembolsa a los productores una tercera parte del capital invertido en las producciones nacionales. Por otro, los productores españoles se benefician de los incentivos que ofrece la Unión Europea a través del Fondo Euroimages (creado en 1988), el Media Programme (1991) y Europa Cinemas (1993). Por supuesto, habría que añadir también que muchos países latinoamericanos, a su vez, han recuperado las ayudas del sector público, que perdieron a comienzos de los 90, y han comenzado a beneficiarse de los frutos de los últimos intentos de crear un mercado común latinoamericano (como es el caso de MERCOSUR).

Pero algunas de las críticas más duras (y probablemente también las más cuestionables) se refieren al valor estético de las coproducciones y a la supuesta pérdida de las señas de identidad que conlleva su potencial de exportación. Se ha señalado a menudo que estos filmes padecen diferentes niveles de descontextualización social y cultural. Uno de los elementos más problemáticos en este sentido ha sido la obligatoriedad durante muchos años de incorporar actores españoles con la única intención de cumplir los mínimos de cuota especificados en el contrato de coproducción. El marcado acento de los actores revela de inmediato el carácter coproducido del filme, creando un cierto efecto de desfamiliarización (Villazana 2008: 78). Para naturalizar este tipo de imposiciones, se tiende a escoger una de estas fórmulas: o bien la presencia del actor español queda justificada en el guion haciendo que se trate de un personaje nacido en España y forzado a emigrar a Latinoamérica (el caso de José Luis López Vazquez en Luna de Avellaneda); o bien los actores españoles tienen que imitar el acento del país latinoamericano donde se desarrolla la acción (el caso de Unax Ugalde, emulando el acento paisa en Rosario Tijeras $)^{16}$. El resultado son filmes híbridos

\footnotetext{
15 Lo cierto es que probablemente este déficit no sería difícil de resolver si el Fondo ampliara aún más su horizonte transnacional. Países como Francia, Italia e incluso la MPAA norteamericana han solicitado formar parte de Ibermedia, pero las administraciones españolas se han negado al considerar que esto pondría en entredicho el espíritu iberoamericano del consorcio, algo que confirmaría el valor de hegemonía cultural que España podría buscar en el proyecto (Vidal Villegas 2000).

${ }^{16}$ Es esta una regulación que ha sido frecuentemente contestada, hasta el punto de haber sido resuelta, el menos en parte, durante las últimas convocatorias, que contemplan la posibilidad de
} 
en los que las identidades se diluyen y transforman dentro de narrativas globales que tanto en su forma como en su contenido adquieren una naturaleza transnacional. Este tipo de mutaciones debe ser entendido dentro de los procesos de desterritorialización con que se caracteriza el mundo de la cultura en la era de la globalización (Appadurai 1996: 37-39; García Canclini 1990: 288-305; Tomlinson 1999: 106-149).

A pesar de las críticas recibidas, que podrían hacerse extensivas a la mayoría de las coproducciones, los críticos y profesionales del medio han ido adoptando una visión cada vez más positiva de la trayectoria de Ibermedia. El Fondo, a su vez, ha ido incorporando muchas de las sugerencias y reclamos efectuados a lo largo de todos estos años. El aspecto más valorado del proyecto es, sin duda, el hecho de que ofrece un marco estable para la producción cinematográfica, frente a la volatilidad con la que se han caracterizado siempre las políticas de apoyo al audiovisual latinoamericano (Falikov 2012: 307). Cuando en el pasado las subvenciones estatales se canalizaban a través de los Institutos de Cine nacionales, se producían ciclos de bonanza y precariedad, dependiendo de la situación económica de cada país y de las políticas culturales del gobierno de turno. La volatilidad de aquel sistema presenta un fuerte contraste con el Programa Ibermedia, que ha demostrado ser un modelo sólido y consistente. Cualquier país que gana una competición puede seleccionar otro país o países con quienes colaborar en régimen de coproducción. Podría pensarse que solo los países más ricos serían seleccionados. Sin embargo, como ya señalé, una de las ventajas de escoger países más pobres radica en los bajos costes de producción, lo que supone un considerable ahorro en los gastos de rodaje. En países como Cuba la producción cinematográfica sería prácticamente impensable en estos momentos sin la ayuda de Ibermedia (y de otros proyectos de coproducción con Europa). Esto es algo que a veces resienten algunos realizadores, pero incluso aquellos más renuentes reconocen en la fórmula de Ibermedia una de las pocas alternativas para la supervivencia del sector. El director cubano Julio García Espinosa, crítico de algunos aspectos de este sistema, ha admitido también sus ventajas para el mantenimiento de las débiles industrias cinematográficas en Latinoamérica y para el desarrollo profesional de los técnicos locales (Villazana 2008: 77).

No cabe duda de que el Programa Ibermedia continúa siendo el sistema de financiación cinematográfica más efectivo en Latinoamérica. Sin embargo, como los sistemas de coproducción europeos, está administrado por los Estados Iberoamericanos de tal forma que no termina de trascender los problemas de paternalismo y las dinámicas de poder que surgen cuando se presentan desequilibrios entre los países participantes. A pesar de ello, el programa ha intentado administrarse sobre la base de un sistema bastante equitativo que ha tenido como resultado la producción de filmes de todos los países participantes, sin importar su tamaño o poder económico. Su última inicitativa, Ibermedia TV,

que la cuota mínima de actores pueda ser resuelta con la participación, en su lugar, de un número determinado de técnicos cualificados. 
puede ayudar aún más a diseminar el cine latino, sorteando las limitaciones del sistema de exhibición tradicional en salas, todavía bajo el control mayoritario de empresas norteamericanas ${ }^{17}$. Aprobado en la xv Reunión del Comité intergubernamental celebrado en Santo Domingo en 2008, el programa Ibermedia TV consiste en la adquisición de derechos de antena de cine iberoamericano para su emisión en los canales púbicos. Cumpliendo el cronograma previsto, en marzo de 2010 se dio inicio a la emisión de las cincuenta y dos películas que formaban parte de la primera edición del programa con el nombre comercial de "Nuestro Cine / Nosso Cinema" (Programa Ibermedia 2011: 15).

En los últimos años han surgido iniciativas regionales alternativas o complementarias a Ibermedia. CINERGIA (Fondo de Fomento para el Audiovisual de Centroamérica y el Caribe) es una de ellas, creada en 2004 por María Lourdes Cortés, catedrática de la Universidad de Costa Rica y ex directora de la única Escuela de Cine y Televisión (Veritas) en ese país. El proyecto ha sido financiado por Hivos (Holanda), la Fundación Ford, la misma Escuela Veritas, y otros apoyos puntuales como el del Göteborg International Film Festival Fund (Suecia) y la Fundación del Nuevo Cine Latinoamericano, fundada en 1985 por García Márquez y con sede en La Habana. Las actividades de la organización se centran en tres áreas fundamentales: 1) convocatoria de proyectos; 2) talleres y encuentros; 3) portal centroamericano de cine, vídeo y animación. Anualmente se convocan en diversas categorías proyectos audiovisuales, que un comité especializado evalúa y selecciona para su financiación ya sea mediante becas o dinero en efectivo. CINERGIA organiza, además, talleres y encuentros entre los profesionales de la región para su formación en todas las áreas del audiovisual. Estos talleres corren a cargo de organizaciones como TyPA-Teoría y Práctica de las Artes (Argentina) y el Visionary Talent Campus, del Festival Internacional de Cine de Guadalajara. Mediante su "Portal Centroamericano de Cine, Video y Animación", la organización mantiene un portal de Internet cuya función es servir de ventana para la producción audiovisual de Centroamérica. En los últimos diez años CINERGIA ha apoyado más de sesenta filmes, entre cortos, animaciones, largometrajes de ficción y documentales, los cuales han ganado más de ciento veinte premios internacionales. Además, se han realizado veintisiete talleres internacionales y se han otorgado veinte becas y asesorías.

Si bien CINERGIA es un proyecto mayoritariamente latinoamericano, el caso de la productora argentina Patagonik, fundada en 1996 por Pablo Bossi, es un caso mucho más complejo en el que se entrecruzan todo tipo de iniciativas transnacionales. En sus productos se dramatiza a veces la secular competencia entre Europa y Norteamérica por dominar el mercado latinoamericano. Así, en Patagonik participa tanto el capital estadounidense (a través de Buena Vista International), como el español (mediante la presencia de Telefónica Media). In-

\footnotetext{
17 Como señala García Canclini (2005), "[m]ientras este país [EE.UU.] exige absoluta liberación de los mercados, sin cuotas de pantalla ni ninguna política de protección para las películas nacionales, el sistema de distribución y exhibición estadounidense combina varios factores para favorecer a los filmes de su país: exención de impuestos y otros incentivos a sus propias empresas, la organización semimonopólica de la distribución y la exhibición".
} 
cluso Ibermedia ha participado también de forma más o menos encubierta en algunas de sus coproducciones. Su ámbito de trabajo incluye actividades tan dispares como la producción del filme Evita (EE.UU., 1996) de Alan Parker, del vídeo musical de Madonna "Love Don't Live Here Anymore" (EE.UU., 1996) o de películas infantiles como Dibu (Argentina, 1997). De las más de treinta producciones realizadas a lo largo de estos años, las más populares y galardonadas fueron El hijo de la novia (Argentina/España, 2001), de Juan José Campanella, y la ya mencionada Nueve Reinas (Argentina, 2000), de Fabián Bielinsky, ambas ganadoras de más de treinta premios internacionales. Como parte del Grupo Clarín, Patagonik colabora también en la producción de filmes internacionales que se ruedan en Argentina y en la de varios programas de TV.

Otras dos iniciativas que han acaparado el interés de los profesionales del medio son el Programa MERCOSUR Audiovisual y el Foro EGEDA (Entidad de Gestión de Derechos de los Productores Audiovisuales). El primero forma parte de la Reunión Especializada de Autoridades Cinematográficas y Audiovisuales del MERCOSUR (RECAM), órgano consultor del MERCOSUR (Mercado Común del Sur) en todo lo referente al audiovisual. La Entidad Ejecutora del Programa es el Instituto Nacional de Cine y Artes Audiovisuales (INCAA) de la Argentina. El proyecto se presenta como una alternativa autóctona plenamente latinoamericana frente a los sistemas de coproducción con España y los EE.UU., pero lo cierto es que la financiación de MERCOSUR Audiovisual, no solo procede de los gobiernos sudamericanos que forman parte de la organización (Argentina, Bolivia, Brasil, Paraguay, Uruguay y Venezuela), sino que también incluye fondos de la Unión Europea. Y es que en estos momentos de crecimiento exponencial de las iniciativas transnacionales, resulta ya impensable cualquier proyecto limitado a rígidas fronteras nacionales, regionales, o incluso pan-regionales. Por lo que se refiere al Foro EGEDA, su primer encuentro tuvo lugar en Panamá, del 24 al 26 de abril de 2012, y ofrece el último de los espacios creados para el diálogo intelectual y comercial sobre el audiovisual iberoamericano. El Foro aspira a congregar a los principales agentes del sector para debatir y planificar la respuesta del sector a los principales retos en la región: transformar la industria audiovisual iberoamericana y convertirla en el principal instrumento para la promoción de su cultura en el marco del nuevo modelo de mercado.

\section{CONCLUSIÓN}

Hasta hace muy poco decir identidad era hablar de raíces, de raigambre, territorio, y de tiempo largo, de memoria simbólicamente densa. De eso y solamente de eso estaba hecha la identidad. Pero decir identidad hoy implica también [...] hablar de redes, y de flujos, de migraciones y movilidades, de instantaneidad y desanclaje. (Martín Barbero 2002: 8)

A la pregunta que lanzababa García Canclini en 1993 (“¿Habrá un cine latinoamericano en el año 2000?") le da respuesta él mismo en un reciente artículo: "Cuándo hay cine iberoamericano" (2010). Su contestación es ambivalente porque ni el concepto de "cine latinoamericano" es el mismo hoy que 
hace veinte años, ni tampoco lo es exactamente el de "cine" (crecientemente desplazado por el más génerico y abarcador "audiovisual") o incluso el de "lo latinoamericano". García Canclini hace un breve repaso por la naturaleza crecientemente desterritorializada del mercado cinematográfico iberoamericano. Tras comentar la anécdota del fervor patriótico despertado en Argentina por la concesión del Óscar a El secreto de tus ojos, de José Campanella, pese a tratarse de una película financiada mayoritariamente por capital español y las negativas reacciones de algunos críticos mexicanos frente al éxito de El laberinto del fauno, de Guillermo del Toro, y Babel, de Alejandro González Iñárritu, por considerarlas obras de autores cuyo trabajo en el extranjero recuerda el fracaso de la industria mexicana, se pregunta: ¿qué es lo que marca la nacionalidad de una película?, ¿el lugar donde se desarrolla la trama?, ¿la nacionalidad del director y los actores?, ¿el origen de los recursos económicos?, ¿el estilo narrativo, que algunos juzgan expresivo de cada cultura? El debate sobre este tipo de cuestiones, concluye García Canclini (2010), es estéril porque "depende de un modo de preguntar por las identidades nacionales y por la definición de lo iberoamericano propia de una etapa de la teoría de la cultura que ha mostrado ser improductiva".

Tal y como sugieren las nuevas tendencias de la antropología cultural, cualquier reflexión sobre las identidades (locales, nacionales, regionales, continentales o de cualquier signo) no puede seguir cimentándose en actitudes esencialistas. Desde la publicación y diseminación internacional de la obra de Benedict Anderson, ha quedado suficientemente claro que las naciones son "comunidades imaginadas" y sus identidades, por tanto, construcciones históricas fluctuantes. En el ámbito del cine, cabría preguntarse no "qué es el cine latinoamericano, sino cuándo hay arte o cine latinoamericano" (García Canclini 2010). A pesar de las sospechas despertadas entre los críticos sobre posibles agendas ocultas en los fondos de coproducción, García Canclini (2010), que anteriormente también había mostrado sus reservas, subraya finalmente los logros de programas como Ibermedia, que con más inversión pública que en otras áreas de la cultura, han facilitado el intercambio de bienes culturales: "Ni las artes visuales, ni la literatura, ni la radio, han contado a escala regional con un programa tan estructurado, que lograra involucrar a España, Portugal y dieciséis países de América Latina"18. Una de las razones que explicarían el éxito del programa radica en que no se sustenta precisamente en la exaltación de las identidades nacionales, sino en la creación de un "espacio audiovisual latinoamericano" que permita el fomento de la integración de empresas y proyectos de la región dentro de redes supranacionales ${ }^{19}$. Por supuesto, este tipo de empresas implica todo tipo de mediaciones y negociaciones en las que entran en juego intereses mercantiles y luchas por la conquista de espacios hegemónicos, pero también es cierto, que, a diferencia

\footnotetext{
${ }^{18}$ A los dieciocho países de los que habla García Canclini en su artículo de 2010 se sumó un año después Paraguay.

${ }^{19}$ García Canclini (2010) hace un repaso de las cifras y concluye con un balance muy positivo de este tipo de iniciativas. En los quince años anteriores a la creación de lbermedia (de 1982 a 1998) solo se habían producido cincuenta y nueve películas entre España y Latinoamérica, mientras que en los siete años posteriores a la creación de Ibermedia se hicieron ciento sesenta y cuatro.
} 
de otros consorcios, Ibermedia ha mostrado una especial sensibilidad para incorporar gran parte de las sugerencias de los profesionales del medio y cuenta con una progresiva implicación de casi todos los países del área. A medio y largo plazo, este tipo de prácticas tendrá como resultado no tanto la desaparición de las identidades cinematográficas de los países participantes o de una supuesta identidad continental, sino su inevitable transformación en entes crecientemente híbridos, con un componente tanto económico como cultural. Al fin y al cabo, las coproducciones de finales del siglo xx y comienos del xxl, como hemos podido ver, son productos emblemáticos de la globalización: sus complejos sistemas de financiación transnacional (que implican tanto lo público como lo privado), sus repartos y equipos técnicos internacionales, y sus locaciones múltiples (a menudo transnacionales), subrayan su condición migrante, híbrida (tanto en la forma como en el contenido) y posnacional. Las cinematografías nacionales seguirán existiendo. El problema no está en que la globalización acabe con ellas, sino en entender cómo reconstruyen sus identidades dentro de nuevos procesos de sincretismo cultural.

\section{OBRAS CITADAS}

Alvaray, Luisela (2011): "Are We Global Yet? New Challenges to Defining Latin American Cinema". En: Studies in Hispanic Cinema, vol. 8, n. ${ }^{\circ}$, pp. 69-86.

Appadurai, Arjun (1996): Modernity at Large. Cultural Dimensions of Globalization. Minneapolis, University of Minnesota Press.

Caballero, Rufo, et al. (2006): Producción, coproducción e intercambio de cine entre España, América Latina y el Caribe. Madrid, Fundación Carolina.

Del Arenal, Celestino (2011): "América Latina en la política exterior española". En: José María Beneyto y Juan Carlos Pereira (eds.): Política exterior española: Un balance de futuro. Madrid, Instituto Universitario de Estudios Europeos CEU / Siglo xxı, vol. 1, pp. 243-306.

Díaz López, Marina (1999): "Las vías de la Hispanidad en una coproducción hispanomexicana de 1948: Jalisco canta en Sevilla". En: Los límites de la frontera: La coproducción en el cine español. VII Congreso de la Asociación Española de Historiadores del Cine. Madrid, Academia de las Artes y las Ciencias Cinematográficas de España, pp. 141165.

Elena, Alberto (2005): Cruce de destinos. Intercambios cinematográficos entre España y América Latina. E-excellence. Disponible en <http://www.liceus.com>. Última visita: 03.06.2013.

Falicov, Tamara L. (2003): "Los hijos de Menem: The New Independent Argentine Cinema, 1995-1999". En: Framework, vol. 44, n. ${ }^{\circ}$ 1, pp. 49-63.

(2010): "Programa Ibermedia: ¿Cine transnacional iberoamericano o relaciones públicas para España? En: Reflexiones, vol. 91, n. 1, pp. 299-312.

García Canclini, Néstor (1990): Culturas híbridas: estrategias para entrar y salir de la modernidad. México D.F., Grijalbo.

(1993a): “¿Habrá cine latinoamericano en el año 2000? La cultura visual en la época

316 Pasavento. Revista de Estudios Hispánicos, vol. II, n. ${ }^{2} 2$ (verano 2014), pp. 297-318, ISSN: 2255-4505 
del postnacionalismo" En: La jornada semanal, 21 de febrero, pp. 27-33.

(1993b): "La cultura visual en la época del posnacionalismo. ¿Quién nos va a contar la identidad?". En: Nueva Sociedad, n. ${ }^{\circ}$ 127, pp. 23-31.

(1999): La globalización imaginada. Barcelona, Paidós.

(2005): "Cultura y comercio: desafíos de la globalización para el espacio audiovisual latinoamericano". En: El espacio audiovisual latinoamericano, 14 de junio. Disponible en <http://www.rnw.nl/espanol/article/globalizai\%C3\%B3n-y-el-espacioaudiovisual-latinoamericano>. Última visita: 03.06.2013.

(2010): "Cuándo hay cine iberoamericano". En: SalonKritik, 6 de junio. Disponible en <http://salonkritik.net/09-10/2010/06/cuando_hay_cine_iberoamericano_1.php>. Última visita: 03.06.2013.

Garretón, Manuel Antonio, et al. (2003): El espacio cultural latinoamericano: bases para una política cultural de integración. México D.F., Fondo de Cultura Económica.

Getino, Octavio (2005): Cine argentino (entre lo posible y lo deseable). Buenos Aires, Fundación CICCUS.

Gubern, Roman (1997): "Pluralismo y comunidad en nuestras cinematografías". En: Primer Congreso Internacional de la Lengua Española. Zacatecas, Centro Virtual Cervantes. Disponible en <http://cvc.cervantes.es/obref/congresos/zacatecas/cine/ponencias/ gubern.htm>. Última visita: 03.06.2013.

Johnson, Randal (2007): "The Brazilian Retomada and Global Hollywood". En: Gastón Lillo y Walter Moser (eds.): History and Society: Argentinian and Brazilian Cinema since the 1980s. Ottawa, Legas Publishing, pp. 87-100.

Juan-Navarro, Santiago (2006): "Una sola fe en una sola lengua: la Hispanidad como coartada ideológica en el pensamiento reaccionario español". En: Hispania, vol. 89, n. ${ }^{\circ}$ 2, pp. 393-400.

Martel, Frédéric (2010): Cultura Mainstream. Cómo nacen los fenómenos de masas. Madrid, Santillana.

Martín-Barbero, Jesús (2002): "La globalización en clave cultural: una mirada latinoamericana". En: Coloquio Internacional Globalismo y Pluralismo, Montreal, 24-27 de abril de 2002. Disponible en <http://www.er.uqam.ca/nobel/gricis/actes/ bogues/Barbero.pdf>. Última visita: 03.06.2013.

Miller, Toby, et al. (2005): El nuevo Hollywood. Del imperialismo cultural a las leyes del marketing. Barcelona, Paidós.

Otero, José María (1999): "El horizonte de las coproducciones". En: Los límites de la frontera: La coproducción en el cine español, VII Congreso de la Asociación Española de Historiadores del Cine. Madrid, Academia de las Artes y Ciencias Cinematográficas de España, pp. 17-27.

Paranaguá, Paulo Antonio (2001): "América Latina, Europa y Estados Unidos: relaciones triangulares en la historia del cine". En: Journal of Film Preservación, n. 62, pp. 9-15.

Pardo, Alejandro (2007): "Coproducciones internacionales españolas: ¿estrategia financiera o expresión multicultural?". En: Comunicación y sociedad, vol. 20, n. 2, pp. 133-173.

Programa Ibermedia (2011): "Informe anual. Ejercicio 2011." Madrid, CACl. Disponible en <http://segib.org/programas/files/2010/01/IBERMEDIA-Informe-anual2011-SEGIB.pdf>. Última visita: 03.06.2013. 
Primer Congreso Hispanoamericano de Cinematografía (1932). Madrid, Hijos de M. G. Hernández.

Ruiz Guzmán, Narce Dalia (2011): "La globalización y exhibición del cine mexicano". En: Imaginario visual, vol. 1, n. ${ }^{\circ}$, pp. 15-20.

Sánchez Ruiz, Enrique E. (1998): "El cine mexicano y la globalización: contracción, concentración e intercambio desigual". En: Julianne Burton-Carvajal et al. (eds.) Horizontes del segundo siglo. Investigación y pedagogía del cine mexicano, latinoamericano y chicano. Guadalajara, Universidad de Guadalajara / Imcine, pp. 101-133.

— (2004): "El empequeñecido cine latinoamericano y la integración audiovisual... (¿panamericana?): fatalidad de mercado o alternativa política". En: Comunicación y sociedad, n. ${ }^{\circ}$ 2, pp. 9-36.

Sock, Ann Marie (1995): "Migrancy and the Latin American Cinemascape: Towards a PostNational Critical Praxis". En: Revista Canadiense de Estudios Hispánicos, vol. 20, n. 1, pp. 19-30.

Urrero Peña, Guzmán M. (2002): "Coproducciones". En: Cinematografías de la semejanza. Centro Virtual Cervantes. Disponible en <http://cvc.cervantes.es/actcult/cine/ historia/coproducciones.htm>. Última visita: 03.06.2013.

Vidal Villegas, Norma (2010): "La salida natural para el cine español es Iberoamérica". En: América Económica Internacional: Semanario de Información Económica y Financiera. Disponible en <http://www.americaeconomica.com/reportajes2/ncine. htm>. Última visita: 03.06.2013.

Villazana, Libia (2008): "Hegemony Conditions in the Coproduction Cinema of Latin America: The Role of Spain". En: Framework, vol. 49, n. ${ }^{\circ} 2$, pp. 65-85. 